\title{
Correction to: Liquid Biopsy for Prognosis and Treatment in Metastatic Colorectal Cancer: Circulating Tumor Cells vs Circulating Tumor DNA
}

\author{
Giorgio Patelli ${ }^{1,2}$. Caterina Vaghi ${ }^{1,2} \cdot$ Federica Tosi $^{1}$. Gianluca Mauri ${ }^{1,2} \cdot$ Alessio Amatu $^{1} \cdot$ Daniela Massihnia ${ }^{1,2}$. \\ Silvia Ghezzi ${ }^{1}$ - Erica Bonazzina ${ }^{1} \cdot$ Katia Bencardino $^{1}$. Giulio Cerea ${ }^{1} \cdot$ Salvatore Siena ${ }^{1,2}{ }^{(1)}$. \\ Andrea Sartore-Bianchi ${ }^{1,2}{ }^{10}$
}

Published online: 31 March 2021

(c) Springer Nature Switzerland AG 2021

\section{Correction to: Targeted Oncology} https://doi.org/10.1007/s11523-021-00795-5

The details for the author Salvatore Siena were published without his ORCID ID in the original article. The ORCID ID for Salvatore Siena is 0000-0002-2681-2846.

The original article can be found online at https://doi.org/10.1007/ s11523-021-00795-5.

Andrea Sartore-Bianchi

andrea.sartorebianchi@unimi.it

1 Niguarda Cancer Center, Grande Ospedale Metropolitano Niguarda, Milan, Italy

2 Dipartimento di Oncologia ed Emato-Oncologia, Università degli Studi di Milano (La Statale), Piazza Ospedale Maggiore, 3, 20162 Milan, Italy 